\title{
Editorial
}

\section{Charging for non-core facilities services: The case of hospital car parking}

Journal of Retail \& Leisure Property (2010) 9, 261-262. doi:10.1057/rlp.2010.19

What people often do not understand about Facilities Management is that it is essentially the provision of non-core activities that support the core function of a business or organisation. Hence, the place to start in understanding hospitals is in clearly defining the core business. In most organisations it is fairly easy to do. Toyota manufacture cars, Barclays sell financial products and GSK manufacture drugs. But hospitals are more problematic. It will seem odd to some people that this is important and it will seem strange to others that we should be unable to define it easily. Take the example of Ryanair. The core business is to move people from one place to another. It is not to operate planes or to provide customer satisfaction. The Ryanair business model takes all non-core activities and charges for as much of it as possible on the basis that the core business operation (the transit) can be provided at as low a cost as possible. Hence, you will now pay to physically check in at an airport or to put a bag in the hold. Ryanair are now even considering charging for the use of toilets on board aircraft. The charging for non-core services makes you think about whether you really need them. It is human nature to take what is provided free of charge. Most travellers have never turned down a 'free' meal on an aircraft but have often chosen not to buy one on an airline like Ryanair. And that is the point, they are not really free at all as we have already paid for them in the fare.

\section{HOSPITAL CAR PARKS}

Returning to hospitals and trying to define their core organisational function. Running car parks is clearly not the core business of a hospital. It is a peripheral support service that may be essential for the hospital to operate efficiently but it would and could not operate in isolation. What we are looking for is an interface between the core and non-core functions, a point at which the support services end and the core business begins. Once you leave the car park and walk into the building you will be met by a whole host of other services. In the Edinburgh Royal Infirmary, for example, you will find shops that sell, among other things, food and drink. This is a support service. It is not core and it is not free. The floor upon which you walk has been cleaned. This is a support service but you are not charged. The lights in the corridor are a support service but you are not charged. The use of TV and telephone services in wards is not core and is often charged to patients. As we move closer to 
the core service it becomes harder to be certain. In Cuba, people are expected to bring their own bed linen. This strongly suggests that it is a clear non-core activity and yet in the United Kingdom generally it is not charged. If we jump over the interface between core and non-core activities to look at it from the other side it is clear that a surgeon operating or consultant diagnostic meetings are core business. It is arguable that there are other services that are less clear. Certain aspects of nursing care for example might be viewed as non-core whereas others are clearly core. Any service that can be defined as non-core can be outsourced and any service that can be outsourced can be separately charged.

The question becomes do we want the UK National Health Service (NHS) to provide a basic state treatment service or do we want it to provide all the support services as well? We could examine all the current legislation that governs hospital administration and argue that charging is necessary or we could take the view that there is an overriding principle of free provision of care.

\section{CATEGORIES OF BUILDING USERS}

Another possible approach is to look at the building users. Should we be treating staff, visitors and patients in a different way?

In universities many staff pay charges for car parking. Nobody likes it and people respond to it in different ways. Some will reluctantly pay and others will use public transport. Where public transport is a viable option the opposition will not be as fierce. However, in hospitals, where shifts finish late at night, there are clearly security issues, which may be more important for the Trust to address than the cost. The fact remains however that there are precedents in other businesses for staff being charged for car parking.

Visitor car park charging may be annoying but it cannot be seen as a core part of the NHS treatment service. The problem is defining what is meant by a visitor. If a friend brings a sick friend to hospital are they a visitor? If you cannot differentiate in reality, you cannot differentiate in charges. There are numerous sub-categories of visitor, all of whom it may be argued might be treated differently. We already discriminate in favour of disabled visitors. Should we then not differentiate in favour of the parents of a terminally ill child? If not, who makes that decision?

Patient charging is a different matter. The patient is the intended beneficiary of the NHS system. Here it is as simple as this: we must decide on the principle of whether NHS care begins at the gate or the operating theatre.

Hospital managers can argue that budget cuts and certain legislation make charging for non-core services in hospitals unavoidable. It cannot be argued that funding should be spent on peripherals rather than key services. Therefore, if we want a wider free NHS service we have to oppose the wider national funding issue as well as the local allocation of resources.

Michael Pitt Managing Editor Innovation Bartlett School of Graduate Studies, University College, London, UK E-mail: michael.pitt@ucl.ac.uk 